\title{
SELECTION OF BASIC POSITION IN REFILL FRICTION STIR SPOT WELDING OF 2024-T3 AND D16UTW ALUMINUM ALLOY SHEETS
}

\begin{abstract}
One of the important parameters of Refill Friction Stir Spot Welding is the so-called basic position of the tool. This is the arrangement of the pin and sleeve which occurs when the tool is plunged into the material. The basic positions can be divided into two categories. In the first category, the sleeve and the pin are above the sheet surface or below sheet surface and in the second category the pin is retracted within the sleeve or protrudes from it.

The aim of the work was to test four settings of the basic position, and then determine the best setting of the basic position, without changing the other welding parameters. Joints made of an aluminum alloy 2024-T3 sheet having a thickness of $1.0 \mathrm{~mm}$ and an aluminum alloy D16UTW sheet having a thickness of $0.6 \mathrm{~mm}$ were analysed. The best setting of the basic position was determined based on assessment of the force carried in shear test, macrostructure and weld face of the joints.
\end{abstract}

Keywords: Refill Friction Stir Spot Welding, RFSSW, aluminum alloy, basic position

\section{Introduction}

Nowadays, the aviation industry is interested in the development of joining techniques for aluminum alloys as well as titanium and its alloys, which was presented in [1]. These materials are attractive because of their high strength and low density, as pointed out by the authors of $[2,3]$. Aluminium alloys used in aviation are mainly the $2 \mathrm{xxx}$ and $7 \mathrm{xxx}$ series alloys. According to papers [4,5], one method of joining is Friction Stir Welding (FSW) and its variation Refill Friction Stir Spot Welding (RFSSW).

RFSSW joints are produced by a special tool consisting of a pin, sleeve and clamping ring [6,7] (Fig. 1). As presented in paper [8] the RFSSW process is performed in following way (Fig. 2): the tool is set in the base position so that the clamping ring is on the upper surface of the top sheet. Afterwards the rotating sleeve is plunged into the workpieces, but the rotating pin is retracted. The friction of the sleeve and the welding material causes growth of the welding material temperature and the reduction of material yield stress [9-11]. Thereby the plasticized welded material is transferred to the pin location. Upon reaching the desired plunge depth the sleeve is retracted and the pin is lowered. At the same time, the pin presses the material into the place of the raising sleeve [12-14]. Both the sleeve and pin return to the basic position. The final step is to smooth the weld face.

One of the important parameters of Refill Friction Stir Spot Welding is the so-called basic position of the tool. This is the arrangement of the pin and sleeve which occurs when the tool is plunged into the material. The basic position is not associated with any reference system. This is difficult because the tool position cannot be related to the sheet surface.

The first step in the procedure should be to set all the tool elements i.e. the pin, sleeve and clamping ring in one plane and adopt this position as the base set. A contractual origin of the coordinate system should be taken relative to this position of the tool and the basic position of the tool pin and sleeve should refer to it. The basic positions can be divided into two categories. In the first category, the sleeve and the pin are above the sheet surface or below sheet surface and in the second category the pin is retracted within the sleeve or protrudes from it.

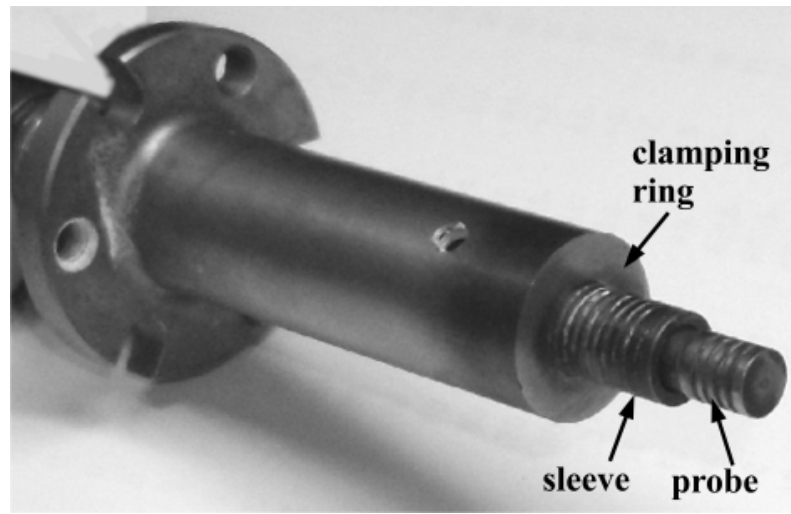

Fig. 1. Tool for RFSSW process [21]

\footnotetext{
* CZESTOCHOWA UNIVERSITY OF TECHNOLOGY, 69 DABROWSKIEGO STR., 42-200 CZESTOCHOWA, POLAND

** PZL MIELEC A SIKORSKY COMPANY, MIELEC, POLAND

\# Corresponding author: aderlatka@bud.pcz.czest.pl
} 

a) base position
b) sleeve pluging
c) sleeve retraction
d) smoothing

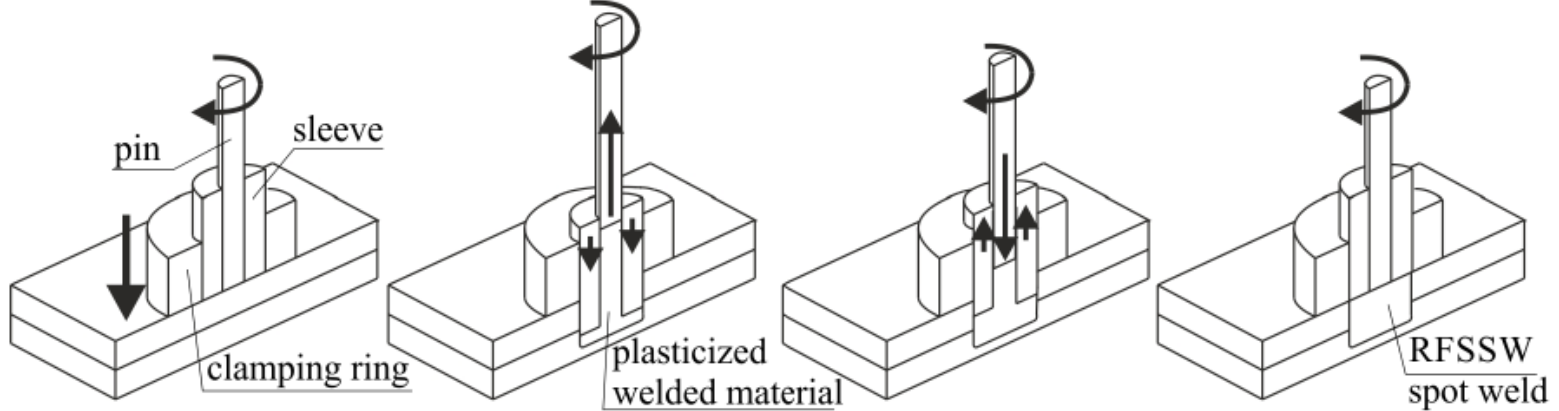

Fig. 2. Stages of RFSSW process

The welding parameters such as time, rotational speed of the tool, displacement of the sleeve and the pin are the second important issue in designing the RFSSW process [15-17]. The movements of the sleeve and the pin are coupled together in such a way that the volume of the plunged portion of the sleeve corresponds to the volume of the space between the top surface of the upper sheet and the end face of the pin. As presented in paper [18] during RFSSW the sleeve should be plunged to approximately 0.1-0.2 mm below the top surface of the bottom sheet.

\section{Goal and scope of work}

The aim of the work was to test four settings of the basic position, and then determine the best setting of the basic position, without changing the other welding parameters. In the first basic position, the sleeve and pin are above the sheet surface and the pin is retracted within the sleeve (Fig. 3a). In the second basic position, the sleeve and pin are below the sheet surface and the pin protrudes from the sleeve (Fig. 3b). In the third position, the sleeve and pin are below the sheet surface and the pin was retracted within the sleeve (Fig. $3 \mathrm{c}$ ). In the last position, the sleeve and pin are above the sheet surface and the pin protrudes from the sleeve (Fig. 3d).

Joints made of an aluminum alloy 2024-T3 sheet having a thickness of $1.0 \mathrm{~mm}$ and an aluminum alloy D16UTW sheet having a thickness of $0.6 \mathrm{~mm}$ were analysed. The geometry of the joints is presented in Fig. 4. For each variant of the basic position, 10 RFSSW welds were made. Nine of them served to assess the load bearing capacity in shear test and one of them was for micro- and macrostructural assessment. Weld face topography was performed for the selected RFSSW welds. A photo of exemplary joints is shown in Fig. 5. The RFSSW parameters used to prepare all the lap joints are presented in Tab 1.

TABLE 1

Parameters used for RFSSW lap joints

\begin{tabular}{|c|c|c|c|c|}
\hline \hline Step & Time, $\mathbf{s}$ & $\begin{array}{c}\text { Rotational } \\
\text { speed, rpm }\end{array}$ & $\begin{array}{c}\text { Sleeve } \\
\text { displacement, } \\
\text { mm }\end{array}$ & $\begin{array}{c}\text { Pin } \\
\text { displacement, } \\
\text { mm }\end{array}$ \\
\hline 1 & 0 & 150 & -0.3 & -0.4 \\
\hline 2 & 2 & 1500 & 0 & 0 \\
\hline 3 & 1.2 & 1500 & 1.1 & -2.196 \\
\hline 4 & 1.5 & 2000 & 0 & 0 \\
\hline
\end{tabular}

\section{Results}

The shear test results of the lap joints made using RFSSW technology are shown in Figs. 6-9 and Tab 2. The maximum forces carried by the joints with one spot weld are presented in the graphs. Reproducible results were observed in each joint group with similar welding parameters since, the confidence interval is $0.2-0.4 \mathrm{kN}$.

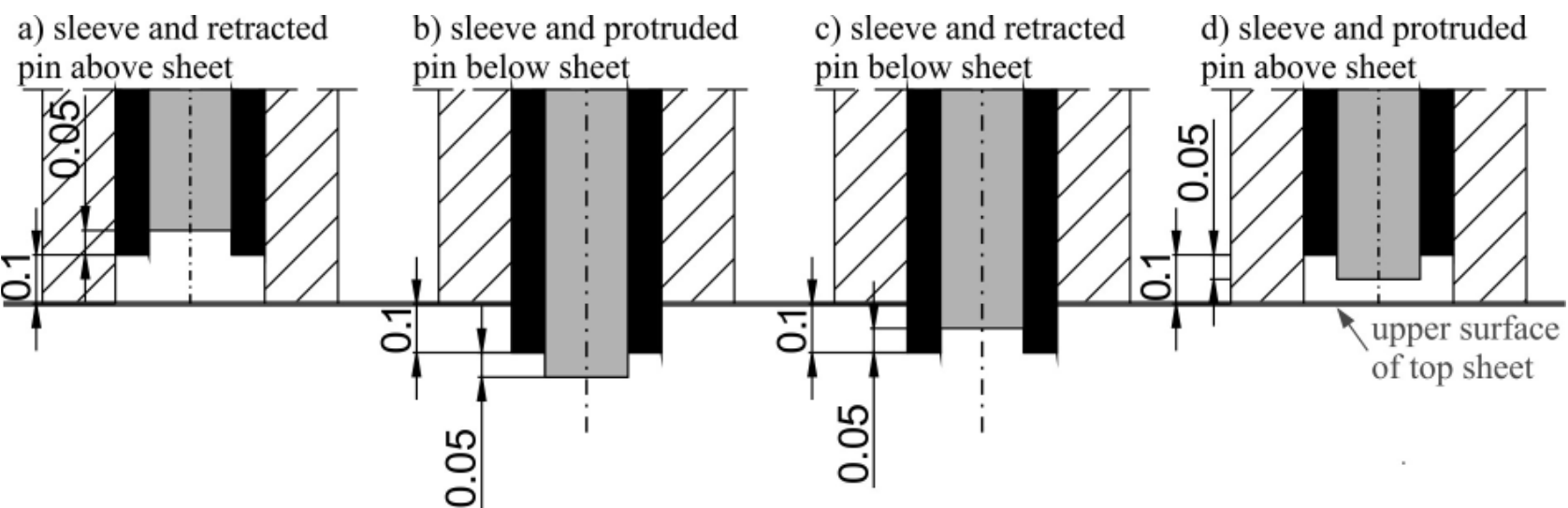

Fig. 3. Diagram of analysed basic positions 


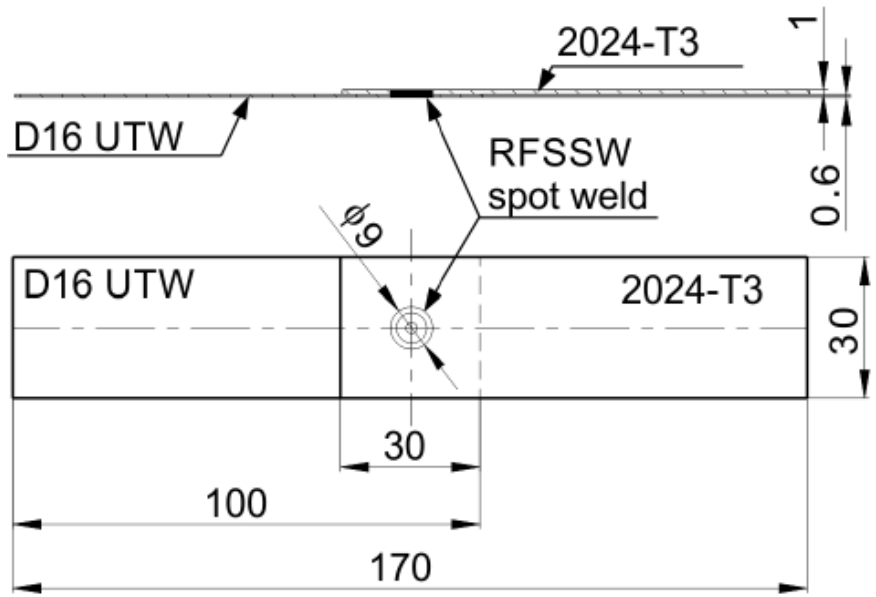

Fig. 4. Geometries of analysed lap joints

The presented graphs show that the RFSSW-136 and RFSSW-173 joints carried the average force of $1.9 \mathrm{kN}$. In those joints the sleeve and the pin in the base position were above the sheet surface. The RFSSW-170 and RFSSW-171 joints carried much higher forces because as the average forces were respectively 3.4 and $3.2 \mathrm{kN}$. In those joints the sleeve and the pin in the base position were below the sheet surface.

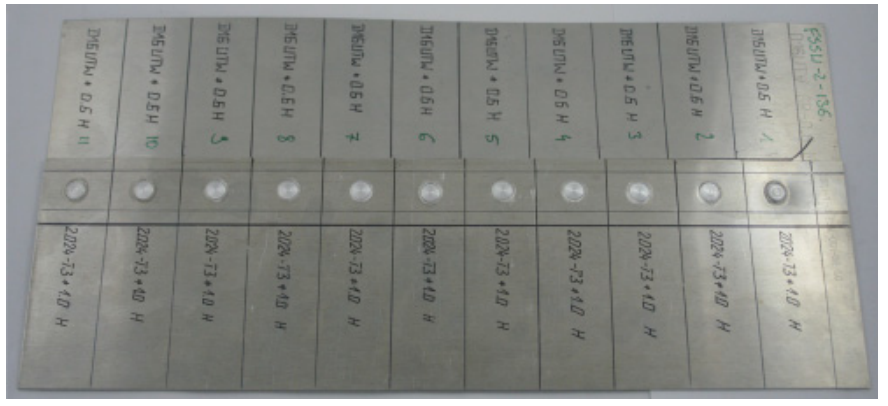

Fig. 5. Photo of exemplary RFSSW lap joints

TABLE 2

Statistics results of load-bearing capacities of RFSSW lap joints

\begin{tabular}{|l|c|c|c|c|}
\hline \hline $\begin{array}{c}\text { Parametry } \\
\text { statystyczne }\end{array}$ & RFSSW-136 & RFSSW-170 & RFSSW-171 & RFSSW-173 \\
\hline Average, kN & 1.9 & 3.4 & 3.2 & 1.9 \\
\hline $\begin{array}{l}\text { Mean absolute } \\
\text { deviation, kN }\end{array}$ & 0.2 & 0.2 & 0.3 & 0.2 \\
\hline $\begin{array}{l}\text { Standard } \\
\text { deviation, kN }\end{array}$ & 0.2 & 0.2 & 0.4 & 0.2 \\
\hline $\begin{array}{l}\text { Confidence } \\
\text { interval }\end{array}$ & $0.5 \%$ & $0.5 \%$ & $0.8 \%$ & $0.4 \%$ \\
\hline $\begin{array}{l}\text { Level of } \\
\text { confidence }\end{array}$ & $95 \%$ & $95 \%$ & $95 \%$ & $95 \%$ \\
\hline
\end{tabular}

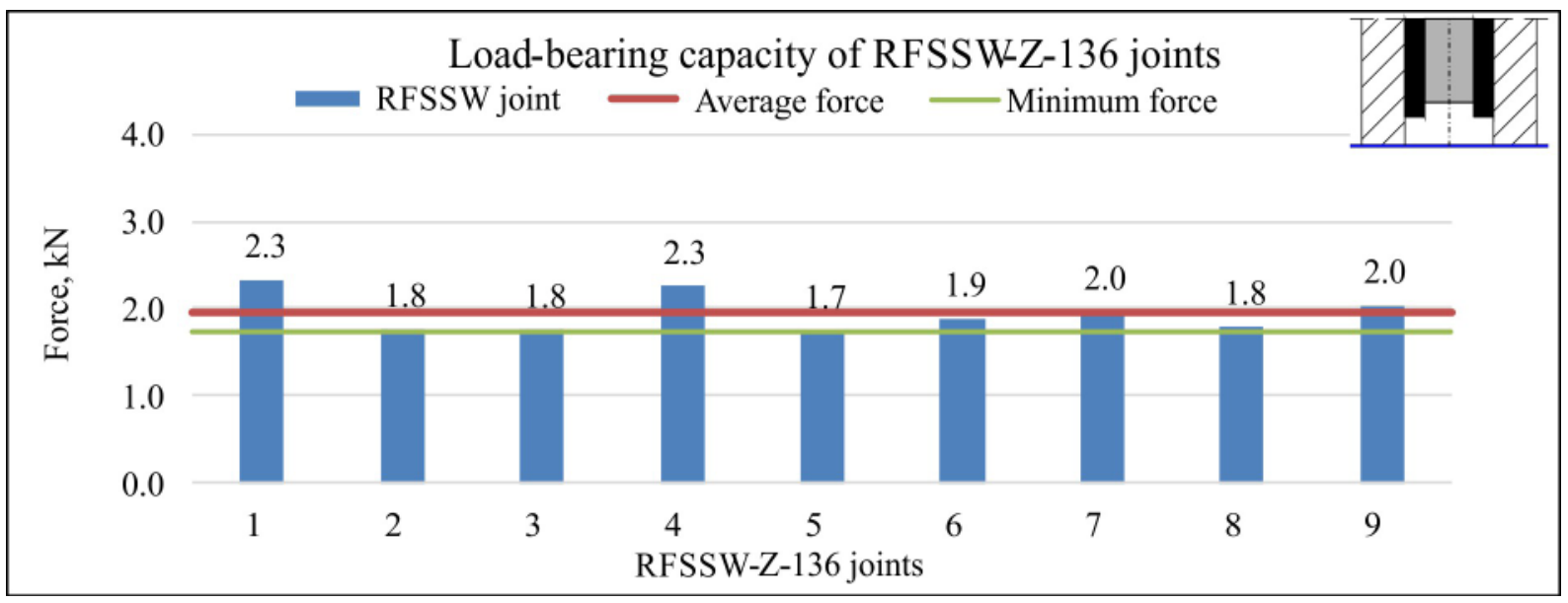

Fig. 6. Force carried by RFSSW-Z-136 joints in shear test

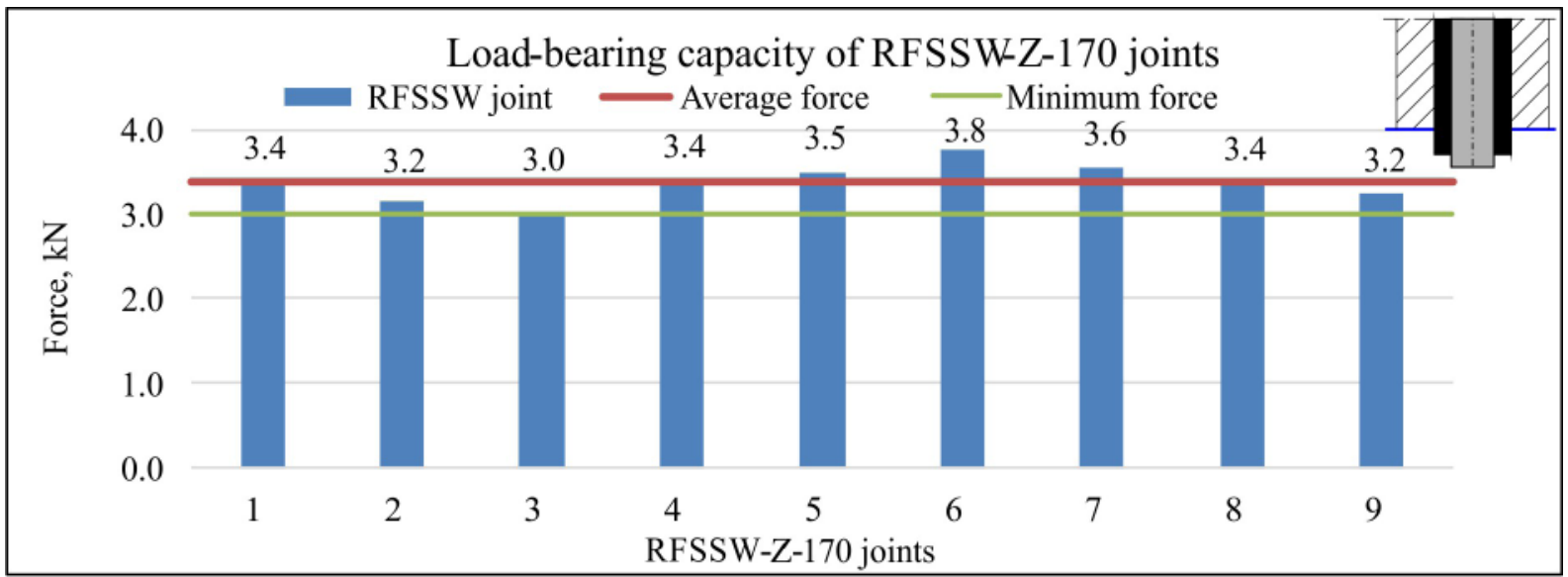

Fig. 7. Force carried by RFSSW-Z-170 joints in shear test 


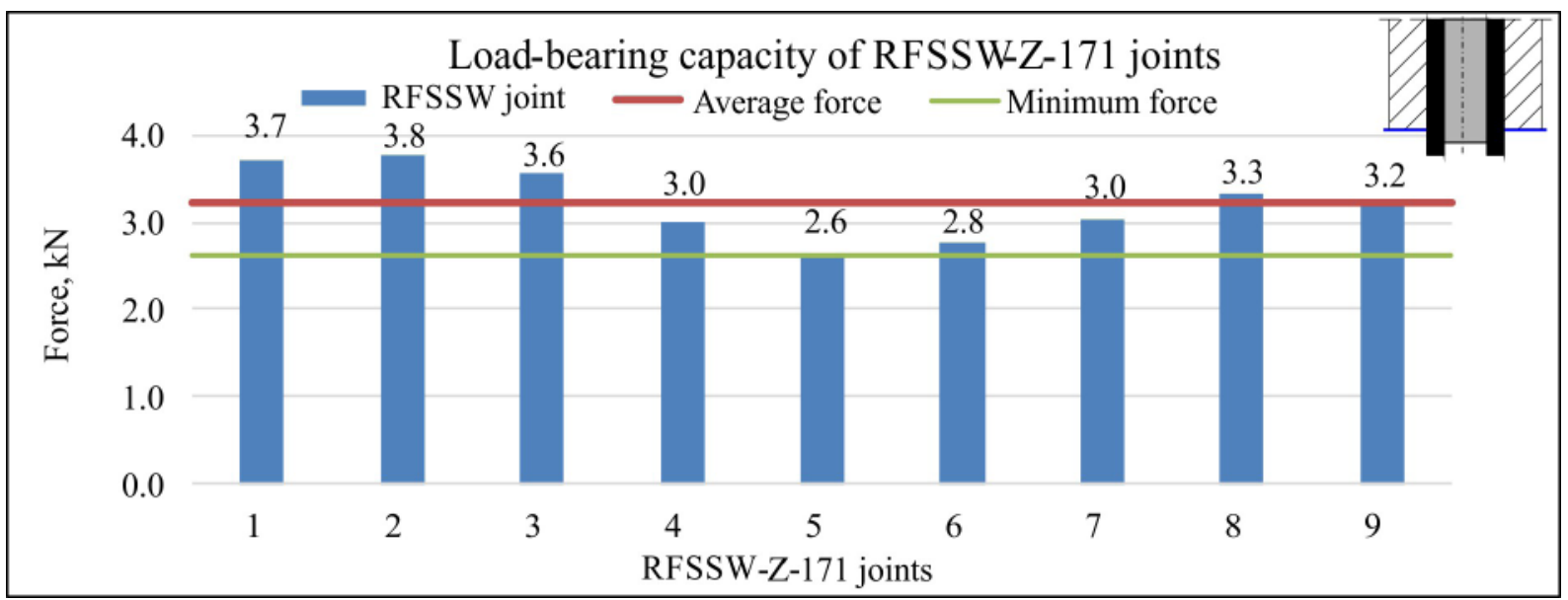

Fig. 8. Force carried by RFSSW-Z-171 joints in shear test

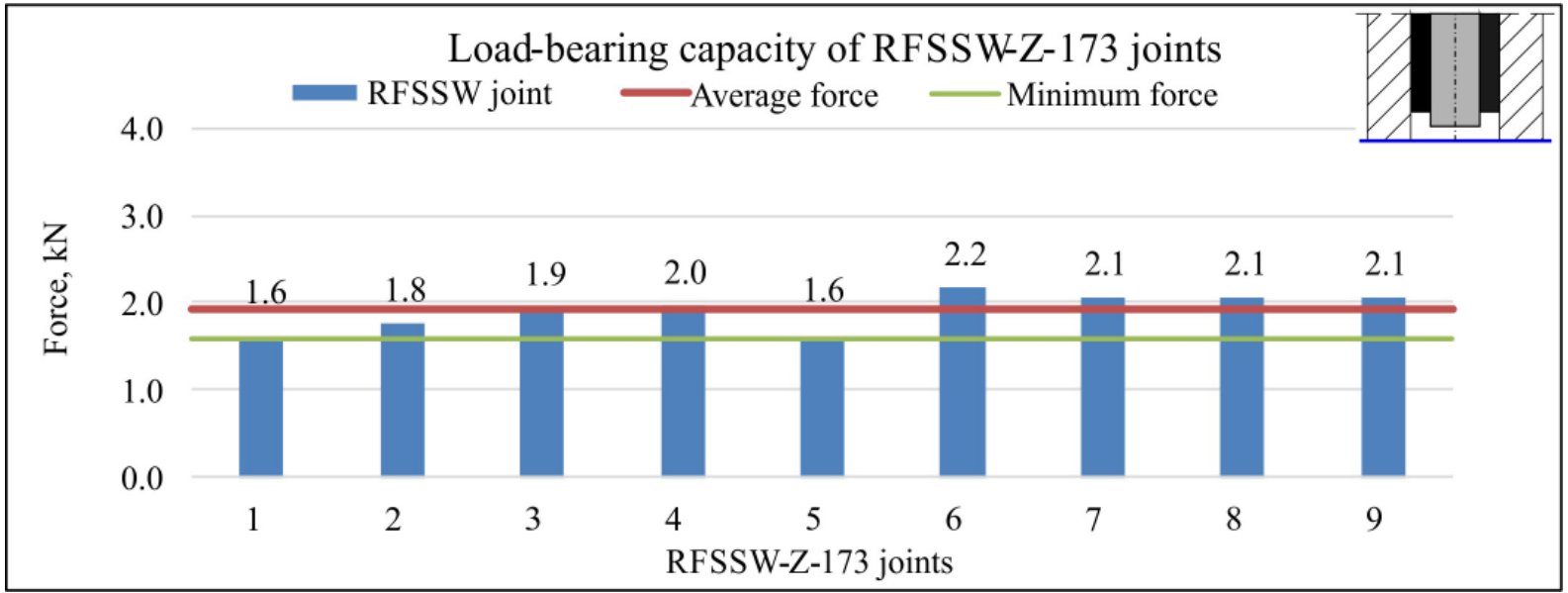

Fig. 9. Force carried by RFSSW-Z-173 joints in shear test

Photos of the macrostructure of the analysed RFSSW joints are presented in Figs. 10-13. In the RFSSW-Z-136.10 and RFSSW-Z-173.10 joints, the material of the top and bottom sheets are not stirred enough. A continuous plating layer is clearly visible. In addition, in the RFSSW-Z-136.10 joint in which the pin in the base position was retracted within the sleeve, there is a wormhole on the bottom surface of the top sheet.

However, in the RFSSW-Z-170.10 and RFSSW-Z-171.10 joints in which the sleeve and the pin in the base position were below the sheet surface, the plating layer is interrupted within

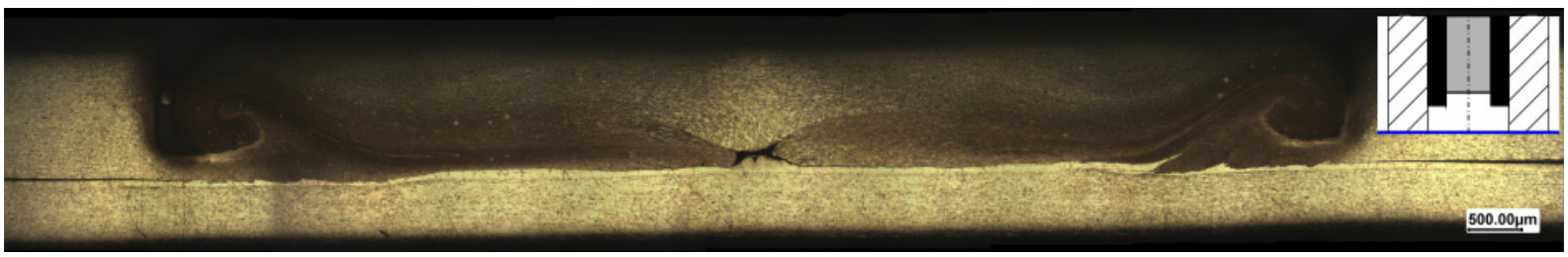

Fig. 10. Macrostructure of RFSSW-Z-136.10 lap joint

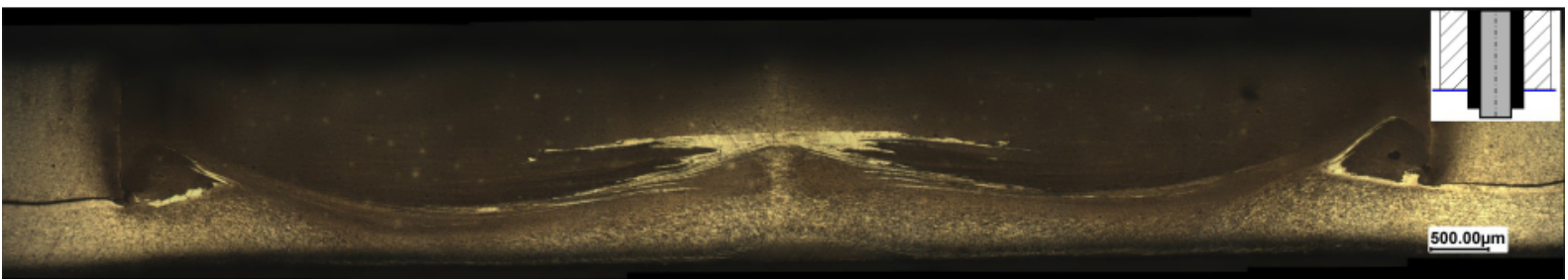

Fig. 11. Macrostructure of RFSSW-Z-170.10 lap joint 


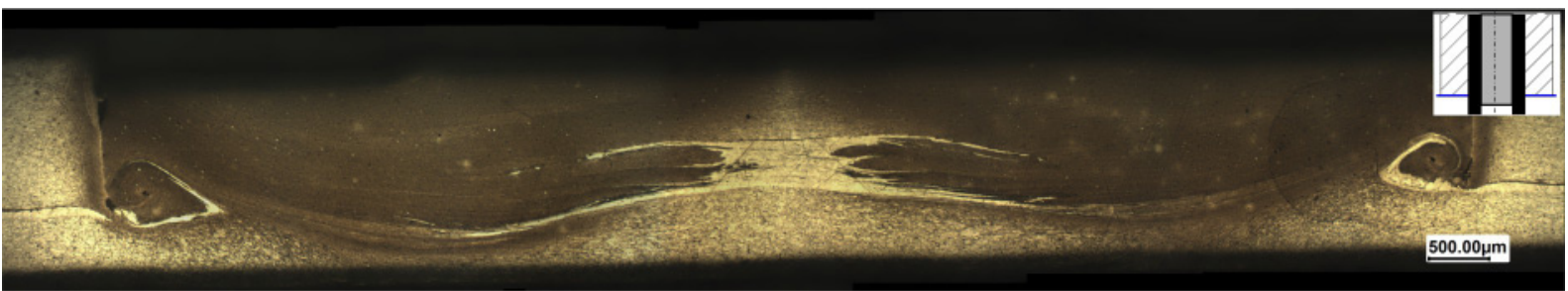

Fig. 12. Macrostructure of RFSSW-Z-171.10 lap joint

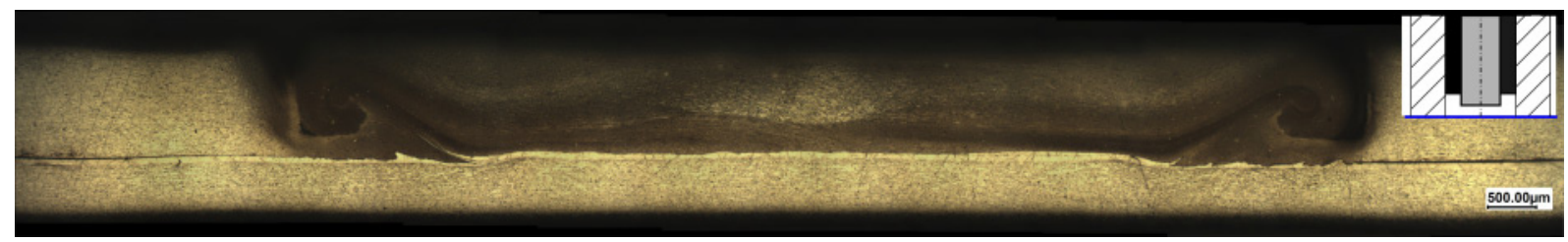

Fig. 13. Macrostructure of RFSSW-Z-173.10 lap joint

the area of the sleeve. The concentration of the plating layer is clearly visible in the pin area.

An important parameter which characterizes a spot weld is the topography of the weld face. The topography of the weld face and the surface profile through the weld centre were made for the RFSSW-Z-136.10 and RFSSW-Z-171.10 spot welds.

In the graph of the RFSSW-Z-136.10 joint (Fig. 14) in which the sleeve and the pin in the base position were above the sheet surface, a notch with a depth of about $200 \mu \mathrm{m}$ is visible.
The notch is in the place where the outer edge of the sleeve was during welding. The notch is around the whole perimeter of the spot weld. The rest of weld surface is located at a similar level to that of the top sheet.

The topography of the weld face and the surface profile of the RFSSW-Z-171.10 spot weld in which the sleeve and the pin in the base position were below the sheet surface are presented in Fig. 15. The topography maps of the weld face (Fig. 15a) show that the spot weld is located in a depression in respect to

a)

b)

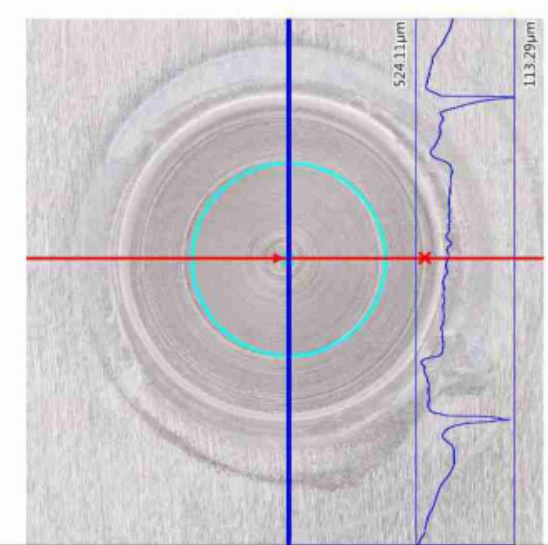

c)

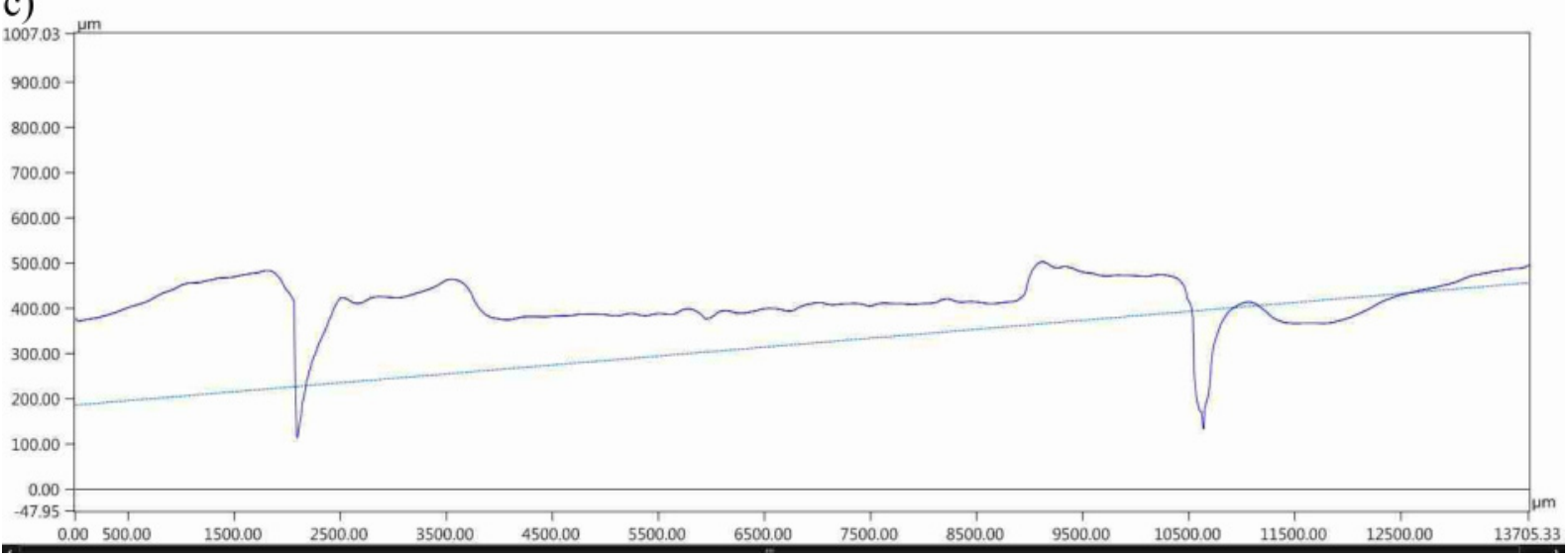

Fig. 14. Assessment of RFSSW-Z-136.10 joint weld face: a) view, b) longitudinal profile 
a)

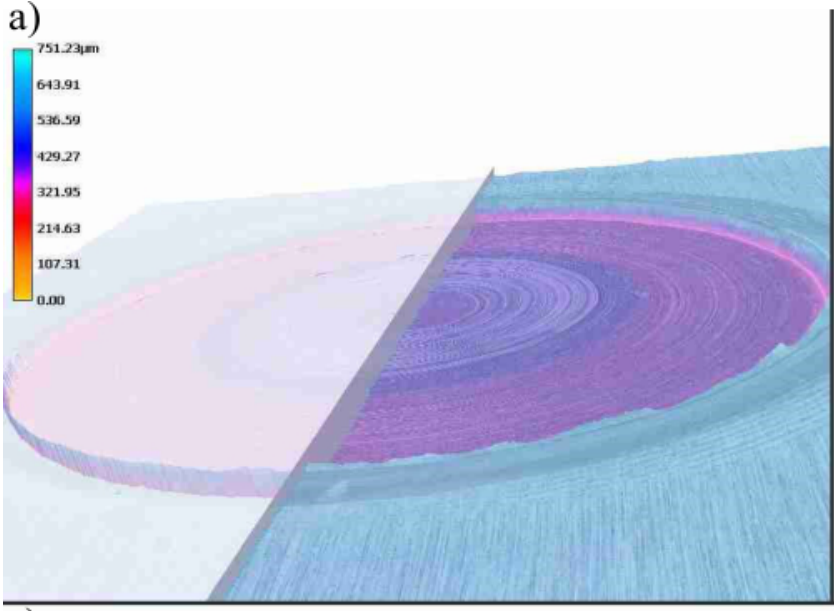

c) b)

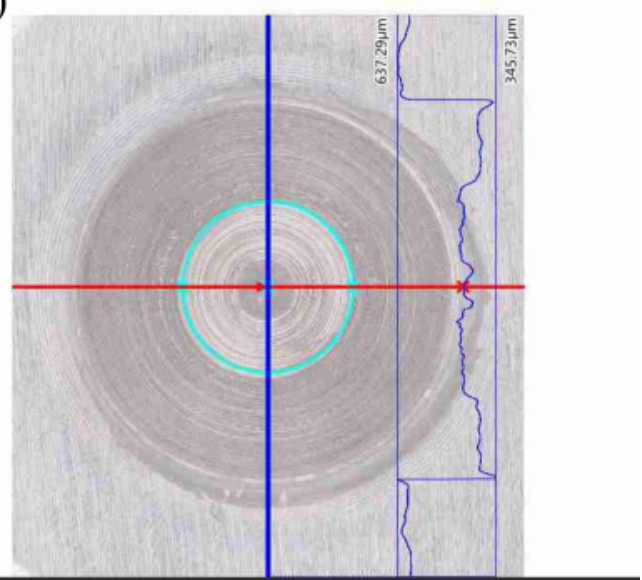

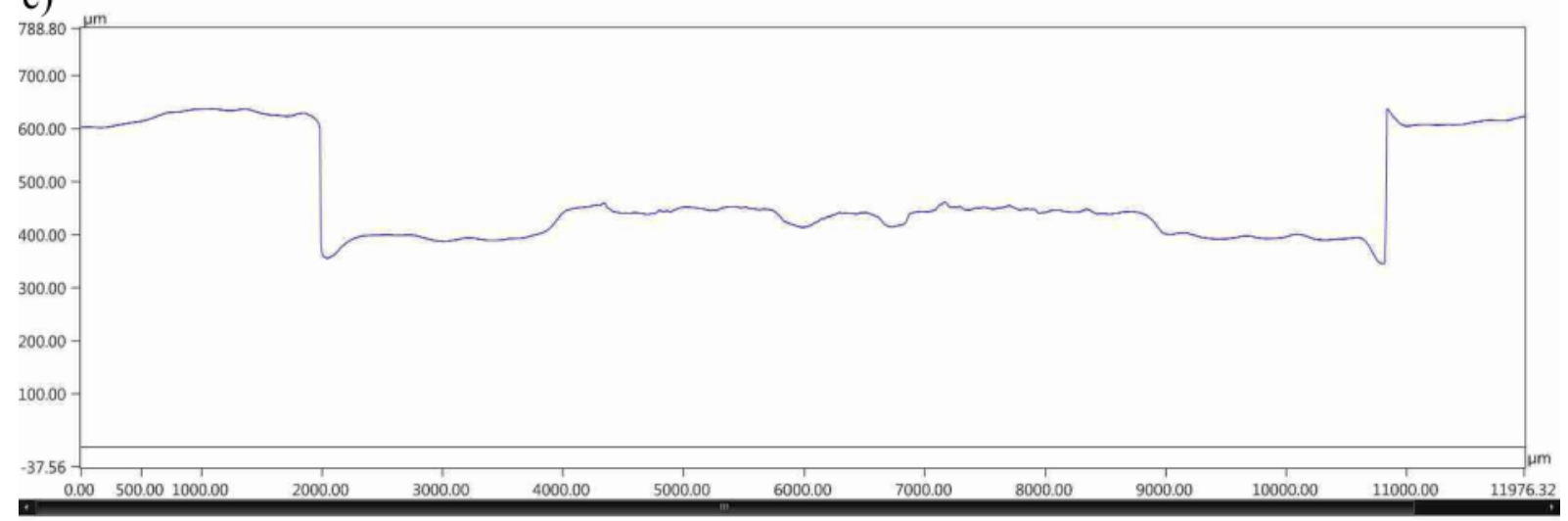

Fig. 15. Assessment of RFSSW-Z-171.10 joint weld face: a) view, b) longitudinal profile

the sheet surface. The surface profile (Fig. 15b, c) allows one to accurately assess the size of the depression. The spot weld is located about $300 \mu \mathrm{m}$ below the sheet surface.

\section{Discussion}

The joints in which the sleeve and the pin in the base position were above the sheet surface carried shear forces of a value under $2.0 \mathrm{kN}$. In those joints there was no stirring of the lower metal sheet because the tool did not plunge below the plating layer. The unstirred layer of the material does not have adequate shear capacity. The joints are formed only through the adhesion of the sheets to each other.

In addition, in the joint in which the pin in the base position was retracted within the sleeve, a wormhole developed on the bottom surface of the sheet. The wormhole is in the place where the pin was during welding. The wormhole occurred because the pin did not press material deep enough.

A notch is made in the joints in which the sleeve and the pin in the base position were above the sheet surface. The notch is the result of unfilled space after retreating the sleeve. Such a type of notches may adversely affect fatigue tests results.

The basic position in which the sleeve and the pin are located below the sheet surface created joints that carried forces over above $3.0 \mathrm{kN}$. The average force $(3.4 \mathrm{kN})$ carried by the joint with the protruding pin in the base position was higher than the force $(3.2 \mathrm{kN})$ carried by the joint with the retracted pin in the base position. Interruption of the plating layer and stirring of the material of both welded sheets occurred in those joints.

The spot weld in which the surface of the face weld is located below the sheet surface was made with the base position in which the sleeve and the pin were below the sheet surface. The profile of the weld face is a parameter influencing the quality of the weld. Therefore, the position of the tool in the base position should be corrected in order to even the weld and sheet surfaces. The profile of the weld face is associated not only with the basic position, but also with other welding parameters. However, at this stage of research only the impact of the base position was analysed. Other welding parameters were assumed as constants

\section{Conclusions}

- The best basic position is the position in which the sleeve and the pin are below the sheet surface and the pin protrudes from the sleeve. The joints made with that base position carried an average force of $3.4 \mathrm{kN}$.

- In the joints performed with the base position in which the sleeve and the pin are below the sheet surface, the welded material of both the connected sheets is stirred. The surface 
of the weld face is smooth, but it lies below the surface of the top sheet.

- The basic position in which the sleeve and the pin are located above the sheet surface created joints that carried a small force with a value under $2.0 \mathrm{kN}$.

- In the joints made with the base position in which the sleeve and the pin are located above the sheet surface, there is no stirring of the lower metal sheet material. Such joints are formed through the adhesion of the sheets to each other. In addition, the notch is found on the surface of the weld face.

\section{Acknowledgements}

Financial support of The National Centre for Research and Development, European Union, PZL Mielec / a Sikorsky Company, in the framework of European Regional Development Fund Project "Advanced techniques for the fabrication of airframe structures using innovative friction stir welding (FSW) technology", no. INNOLOT/I/4/NCBR/2013 is gratefully acknowledged.

\section{REFERENCES}

[1] P. Lacki, K. Wojsyk, K. Kudła, R.E. Śliwa, in: Eberhardsteiner J, H.J. Böhm, F.G. Rammerstorfer (Eds.), Vienna, Austria (2012).

[2] J. Adamus, P. Lacki, M. Motyka, Arch. Civ. Mech. Eng. 15, 1, 42-47 (2015).

[3] J. Adamus, Adv. Mat. Res. 1020, 9-14 (2014).

[4] A.C.F. Silva, D.F.O. Braga, M.A.V. De Figueiredo, P.M.G.P. Moreira, Int. J. Adv. Manuf. Technol. 79, 5-8, 805-814 (2015).

[5] P. Lacki, Z. Kucharczyk, T. Walasek, Key Eng. Mat. 687, 155-162 (2016).

[6] P. Lacki, A. Derlatka, Meccanica 51, 2, 455-462 (2016).

[7] A. Derlatka, K. Kudła, K. Makles, Numerical analysis of RFSSW joints in Proceedings of the jointly organised 11th World Congress on Computational Mechanics (WCCM XI): 5th European Con- ference on Computational Mechanics (ECCM V); 6th European Conference on Computational Fluid Dynamics (ECFD VI); Barcelona, Spain, July 20-25, 2014E. Oñate (Ed.), 1st ed.

[8] T. Rosendo, B. Parra, M. Tier, A. da Silva, J.F. dos Santos, T.R. Strohaecker, N.G. Alcântara, Mater. Design 32, 3, 1094-1100 (2011).

[9] A.A.M. da Silva, J.F. dos Santos, T.R. Rosendo, F.D. Ramos, C.C.P. Mazzaferro, M.A.D. Tier, L. Bergmann, J.A.E. Mazzaferro, T.R. Strohaecker. Warrendale, PA: SAE International (2007).

[10] J.A.E. Mazzaferro, T.S. Rosendo, C.C.P. Mazzaferro, F.D. Ramos, M.A.D. Tier, T.R. Strohaecker, J.F. Santos, Soldagem. Insp. 14, 3, 238-247 (2009).

[11] B. Parra, V.T. Saccon, N.G. de Alcântara, T. Rosendo, J.F. dos Santos, Tecnol. Metal. Mater. Min. 8, 3, 184-190 (2011).

[12] A. Derlatka, P. Kasza, Adv. Mat. Res. 1020, 151-157 (2014).

[13] A. Derlatka, P. Kasza, Adv. Mat. Res. 1020, 158-164 (2014).

[14] P.A. Lacki, J.K. Winowiecka, A.M. Derlatka, Theoretical-experimental analysis of aluminum joints spot welded using rfssw technology in Computational Plasticity XIII: Proceedings of the XIII International Conference on Computational Plasticity - Fundamentals and Applications, held in Barcelona, Spain 1-3 September 2015E. Oñate (Ed.), Barcelona: International Center for Numerical Methods in Engineering (CIMNE), 2015.

[15] T. Montag, J.-P. Wulfsberg, H. Hameister, R. Marschner, Procedia CIRP 24, 108-113 (2014).

[16] T. Rosendo, B. Parra, M. Tier, A. da Silva, J.F. dos Santos, T.R. Strohaecker, N.G. Alcântara, Mater. Design 32, 3, 1094-1100 (2011).

[17] A.H. Plaine, U. Suhuddin, N.G. Alcântara, J.F. dos Santos, International Journal of Fatigue 91, 149-157 (2016).

[18] B. Parra, V.T. Saccon, N.G. de Alcântara, T. Rosendo, J.F. dos Santos, Technol. Metal. Mater. Min. 8, 3, 184-190 (2011).

[19] A. Derlatka, P. Lacki, Comput. Method Mater. Sci. 15, 1, 144-149 (2015). 